\title{
The o-type oxidase of the acidophilic methylotroph Acetobacter methanolicus
}

\author{
H. T. Claude Chan and Christopher Anthony*
}

Biochemistry Department, University of Southampton, Southampton SO9 5TU, UK

(Received 17 July 1990; revised 10 October 1990; accepted 25 October 1990)

\begin{abstract}
Membranes of the acidophilic methylotroph Acetobacter methanolicus contained only $b$ - and $c$-type cytochrome and a CO-binding $b$-type cytochrome. An azide-sensitive oxidase that oxidizes cytochrome $c$ and ascorbate/ TMPD was solubilized from the membrane with a mixture of CHAPS and Zwittergent ${ }_{3-12}(1.7$ fold increase in specific activity with $32 \%$ yield). The solubilized oxidase is unusually stable with respect to high ionic strength $(200 \mathrm{mM}-\mathrm{NaCl}$ ) and stable between $\mathrm{pH} \mathrm{4.0}$ and 6.8. Of the two soluble $c$-type cytochromes from $A$. methanolicus only the typical class I cytochrome (cytochrome $c_{\mathrm{H}}$ ) was a good substrate, as was equine cytochrome $c$. The oxidase was partially purified by anion-exchange chromatography but further purification proved impossible. The yield with respect to equine cytochrome $c$ oxidation was $18 \%$, with a 22 -fold purification, but during purification most of the activity with respect to cytochrome $c_{\mathrm{H}}$ and TMPD was lost. Neutral phospholipids had little effect on activity of the oxidase but the charged phospholipids phosphatidylglycerol and phosphatidylserine stimulated activity up to about fourfold. It proved impossible to incorporate the oxidase into active lipoprotein vesicles. During the purification process the $\mathrm{pH}$ optimum for oxidation of cytochrome $c_{\mathrm{H}}$ was unchanged (pH 5.6) whereas that for oxidation of equine cytochrome changed from $\mathrm{pH} 9.5$ to 7.5 and the sensitivity of the oxidase to azide changed from non-competitive to competitive during the purification process. The partially-purified oxidase contained only $b$ type cytochrome, some of which was CO-reactive. It is proposed that the oxidase is a cytochrome co type of oxidase that loses its cytochrome $c$ component during the purification process and is only able to oxidize $c$-type cytochromes if these can be formed into a 'reconstituted' cytochrome co with the partially-purified oxidase.
\end{abstract}

\section{Introduction}

The present paper describes work on an unusual $o$-type oxidase from the acidophilic methylotroph Acetobacter methanolicus, which grows at $\mathrm{pH} 4$ on methanol as its sole carbon and energy source (Steudel \& Babel, 1982; Steudel et al., 1980). As in other methylotrophic bacteria, methanol is oxidized by way of the quinoprotein methanol dehydrogenase, its specific electron acceptor cytochrome $c_{\mathrm{L}}$, and a typical class I $c$-type cytochrome which is oxidized by a membrane oxidase (Anthony, 1982, 1986; Elliott \& Anthony, 1988). Except for the oxidase all these proteins are periplasmic and so operate at $\mathrm{pH} 4$, the $\mathrm{pH}$ of the growth medium. Preliminary observations suggested that this oxidase may be more stable to extremes of $\mathrm{pH}$ and salt concentration compared with cytochrome oxidases in other bacteria.

The bacterial $o$-type oxidases are defined loosely as oxidases having a CO-binding cytochrome $b$, which for

Abbreviations: CHAPS, 3-(3-cholamidopropyl)dimethylammonio1-propanesulphonate; TMPD, $N, N, N^{\prime}, N^{\prime}$-tetramethyl-p-phenylenediamine. convenience is usually referred to as cytochrome $o$ and which is assumed to be the oxygen-reactive site. Cytochrome $o$ was first described in Staphylococcus aureus (Chance, 1953; Castor \& Chance, 1959) and the $o$ type oxidases have since been shown to be the most widely distributed of the bacterial oxidases (Poole, 1983, 1988). They fall into two classes which differ fundamentally with respect to their structure and function (Poole, 1988). These are the cytochrome bo and cytochrome $c o$ classes, which contain haem $b$ and haem $c$, respectively, as their second prosthetic group.

The substrate for cytochrome bo is ubiquinol, and its function is usually relatively azide-insensitive, the $K_{\mathrm{i}}$ for azide being 2-15 mM (Kita et al., 1984; Matsushita et al., 1987; Sone et al., 1990). By contrast, the substrate for cytochrome co is a class I periplasmic cytochrome $c$, whose oxidation is usually particularly sensitive to azide, the $K_{\mathrm{i}}$ for azide being less than $5 \mu \mathrm{M}$ (Froud \& Anthony, 1984; Auton \& Anthony, 1989). Cytochrome co may also be assayed by taking advantage of its ability to oxidize TMPD (usually together with substrate amounts of ascorbate). 
The cytochrome bo of Escherichia coli is the only example of a functional ubiquinol oxidase of this type that has been characterized extensively (Kita et al., 1984; Saraste et al., 1988). E. coli is a facultative anaerobe which, in aerobic conditions, produces neither $c$-type nor $a$-type cytochromes, and it might be reasonable to assume that cytochrome bo would be found only in similar bacteria. However, that bacteria able to synthesize $c$-type cytochromes may also contain cytochrome $b o$ has recently been demonstrated in Gluconobacter suboxydans, from which a ubiquinol-oxidizing cytochrome bo has recently been purified (Matsushita et al., 1987).

Much less is known about the second class of $o$-type oxidase, cytochrome $c o$, although it has been purified from a number of bacteria, including Methylophilus methylotrophus (Carver \& Jones, 1983; Froud \& Anthony, 1984), Azotobacter vinelandii (Yang \& Jurtshuk, 1978; Jurtshuk et al., 1981; Hunter et al., 1989), Rhodopseudomonas palustris (King \& Drews, 1976), and Pseudomonas aeruginosa (Matsushita et al., 1982). Cytochrome $c o$ is sensitive to low concentrations of azide and cyanide, and it oxidizes the high-potential substrates cytochrome $c$ and ascorbate/TMPD, but not the lowpotential substrate ubiquinol. Most reports have described the use of ascorbate/TMPD as substrate for the oxidase and have not investigated oxidation of its physiological substrate, cytochrome $c$.

One of the first to be purified and shown to be a cytochrome $c$ oxidase was the cytochrome co from the obligate methylotroph Methylophilus methylotrophus (Froud \& Anthony, 1984). This has been purified to homogeneity and shown to consist of equal amounts of $b$ and $c$-type cytochromes, corresponding to the two types of protein subunit seen on SDS-PAGE; these had molecular masses of $31.5 \mathrm{kDa}$ and $23.8 \mathrm{kDa}$ respectively. It was also shown that the cytochrome $c$ subunit did not correspond to either of the two soluble cytochromes $c$ from M. methylotrophus (Froud \& Anthony, 1984; Anthony, 1986). The oxidase was found to be very difficult to purify reproducibly and it was unstable (Carver \& Jones, 1983; Froud \& Anthony, 1984).

The present paper characterizes the $o$-type cytochrome of $A$. methanolicus. This study was initiated to consider the following questions. Does the greater stability of the oxidase to extremes of $\mathrm{pH}$ and salt concentration permit reproducible purification of a stable oxidase that can be used for further work on this important oxidase? Is the $o$ type oxidase of this acidophile similar in type to other methylotroph o-type cytochromes with respect to its substrate specificity? And is the $o$-type oxidase similar to that from another acetic acid bacterium, Gluconobacter suboxydans, in being a cytochrome bo operating in an organism which is able to synthesize $c$-type cytochromes?

\section{Methods}

Organism and growth conditions. Acetobacter methanolicus MB58 is the type strain of the species (no. IMET 10945) in the culture collection of the Institute of Microbiology and Experimental Therapy of the Academy of Science of the GDR. It was the kind gift of Professor W. Babel (Institut für Biotechnologie, Leipzig, Germany). Stock cultures were maintained on methanol-containing minimal agar slopes at $4{ }^{\circ} \mathrm{C}$ or in $30 \%(\mathrm{v} / \mathrm{v})$ glycerol at $-20{ }^{\circ} \mathrm{C}$. The defined growth medium was that described by Uhlig et al. (1986), containing methanol $(1 \%, \mathrm{v} / \mathrm{v})$.

Batch cultures of bacteria were grown at $\mathrm{pH} 4.0$ as $500 \mathrm{ml}$ cultures in 2-litre flasks, at $30^{\circ} \mathrm{C}$, on an orbital shaker (LH Fermentation), for about $24-36 \mathrm{~h}$. They were harvested by centrifugation at $6000 \mathrm{~g}$ for $30 \mathrm{~min}$, washed and resuspended $\left(1 \mathrm{~g}\right.$ wet weight $\left.\mathrm{ml}^{-1}\right)$ in $20 \mathrm{~mm}$ Tris/ $/ \mathrm{Cl}$ pH 8.0.

Disruption and fractionation of bacteria. Bacteria were disrupted in an MSE Soniprep 150 ultrasonic disintegrator for 15 cycles each of $30 \mathrm{~s}$ sonication followed by $30 \mathrm{~s}$ cooling. Whole cells and cell debris were removed by centrifugation at $40000 \mathrm{~g}$ for $15 \mathrm{~min}$ and membranes prepared by centrifugation of the resulting cell free extract at $100000 \mathrm{~g}$ for $3 \mathrm{~h}$. The red/orange pellet was washed by suspending it in $25 \mathrm{~mm}-$ MOPS buffer (pH 6.8) containing $500 \mathrm{mM}-\mathrm{NaCl}$, followed by centrifugation for $1 \mathrm{~h}$ at $100000 \mathrm{~g}$. The pellet was washed again in $25 \mathrm{~mm}-$ MOPS buffer (pH 6.8) and was centrifuged at $100000 \mathrm{~g}$ for another $1 \mathrm{~h}$. The pellet containing membranes was then resuspended in a minimum volume of the same buffer and stored in liquid nitrogen.

Solubilization of oxidase. Solubilized oxidase was prepared by stirring membranes (about 8-10 $\mathrm{mg}$ membrane protein $\mathrm{ml}^{-1}$, final concentration) with detergent in $25 \mathrm{~mm}$-MOPS buffer (pH 6.8) containing $10 \%$ $(\mathrm{v} / \mathrm{v})$ glycerol on ice for $30 \mathrm{~min}$. The mixture was then centrifuged at $100000 \mathrm{~g}$ for $1 \mathrm{~h}$ to yield a pellet and supernatant, containing solubilized oxidase. The pellet was resuspended in the same buffer. Both the solubilized oxidase and pellet resuspension were stored in liquid nitrogen or at $-80^{\circ} \mathrm{C}$.

Partial purification of the oxidase. This was a single-step partial purification procedure. Solubilized membrane protein $(24 \mathrm{ml}$ containing $35 \mathrm{mg}$ protein) in $25 \mathrm{~mm}$-MOPS buffer (pH 6.8) containing $10 \%$ glycerol, $25 \mathrm{~mm}$-CHAPS [3-(3-cholamidopropyl)dimethylammonio-1propanesulphonate] and $8 \mathrm{mM}-Z_{\text {wittergent }}$ 3-12 $_{2}$ was applied to a DEAESepharose column $(1.6 \times 8 \mathrm{~cm})$ pre-equilibrated with $25 \mathrm{~mm}$-MOPS buffer (pH 6.8) containing $10 \mathrm{~mm}-\mathrm{CHAPS}$ and $10 \%$ glycerol. The majority of the cytochrome $c$ eluted without binding and no active oxidase was found in this eluate. Cytochrome oxidase was eluted with a stepwise $\mathrm{NaCl}$ gradient. Active fractions (eluted with $0.4 \mathrm{M}-\mathrm{NaCl}$ ) were pooled and concentrated with a Centricon-10 (Amicon) before storage at $-80^{\circ} \mathrm{C}$ or in liquid nitrogen.

Anion-exchange chromatography on Q-Sepharose gave only 16-fold purification, compared with 22-25-fold purification obtained with DEAE-Sepharose. During attempts to purify the oxidase from solubilized membranes by hydroxyapatite chromatography, the oxidase activity was found to 'spread out' among eluted fractions and no purification was obtained. During hydrophobic interaction chromatography on octyl-Sepharose in $1.7 \mathrm{M}-\left(\mathrm{NH}_{4}\right)_{2} \mathrm{SO}_{4}$, the oxidase precipitated. Lower salt concentrations caused the protein to pass through the column without binding. In an attempt to purify further the oxidase from the eluate from DEAE-Sepharose it was exchanged into $0.2 \mathrm{mM}$ dodecyl maltoside/MOPS buffer containing $0.8 \mathrm{M}-\left(\mathrm{NH}_{4}\right)_{2} \mathrm{SO}_{4}$ and applied to an octyl-Sepharose column for hydrophobic interaction chromatography. An orange band was eluted after a major protein band when the column was washed with the above buffer. However, when this was attempted on a larger scale, the orange band formed a precipitate and could not be eluted. 
No activity was recovered after gel filtration on Superose-12 (Pharmacia) in the presence of $25 \mathrm{mM}-\mathrm{MOPS} / 10 \%$ glycerol $/ 10 \mathrm{mM}$ CHAPS $/ 100 \mathrm{~mm}-\mathrm{NaCl}$, even though at least six protein bands were resolved.

Gel filtration on Superose-12 (Pharmacia) in the presence of $25 \mathrm{~mm}$ MOPS (pH 6.8)/10\% glycerol $/ 0 \cdot 2 \mathrm{~mm}$ dodecyl maltoside $/ 100 \mathrm{~mm}-\mathrm{NaCl}$ resolved the partially-purified oxidase into three major fractions, only one of which had a small amount of oxidase, but its specific activity was lower than that of the starting material, and no activity was recovered when this procedure was repeated on a larger scale.

Spectrophotometric assay of oxidase activity. The cytochrome oxidase activity of membrane fractions, solubilized fractions or partiallypurified oxidase was determined spectrophotometrically using a SP8$400 \mathrm{UV} /$ VIS dual-beam spectrophotometer (Pye-Unicam) with cytochrome $c$ by recording the decrease in absorbance at about $550 \mathrm{~nm}$ (using the exact absorption band for each cytochrome $c$ ), and a reference wavelength of $600 \mathrm{~nm}$ in $25 \mathrm{~mm}$-MOPS buffer $\mathrm{pH} 6.8$. Reduced cytochrome $c$ was prepared immediately before use by reduction with ascorbate followed by passage down a pre-packed PD10 column (Pharmacia).

Polarographic assay of oxidase activity. Assays were carried out at $30^{\circ} \mathrm{C}$ in 25 mM-MOPS (pH 6.8). A Clark-type oxygen electrode (Rank Bros) was used with a reaction volume of $2 \mathrm{ml}$. The electrode was calibrated using $2 \mathrm{ml}$ of air-saturated buffer containing $445 \mathrm{nmol}$ oxygen. The oxidase was assayed using an artificial electron donor, $N, N, N^{\prime}, N^{\prime}$-tetramethyl-p-phenylenediamine (TMPD) in the presence of excess ascorbate at concentrations of $0.2 \mathrm{~mm}$ and $2 \mathrm{~mm}$ respectively. When ubiquinol-1 $(100 \mu \mathrm{M})$ (a gift from Hoffman La Roche) was used as electron donor, the $1 \mathrm{ml}$ reaction mixture contained $50 \mathrm{~mm}-\mathrm{Tris} / \mathrm{HCl}$ (pH 7.0), bovine serum albumin $\left(1 \mathrm{mg} \mathrm{ml}^{-1}\right)$ and $0.05 \%$ Tween 20 . Dithiothreitol $(8 \mathrm{mM})$ was used to maintain the quinol in the reduced state.

Measurement of absorption spectra. Absorption spectra were recorded using a Shimadzu UV3000 dual-wavelength/double beam spectrophotometer. Unless otherwise stated, the scan speed was $100 \mathrm{~nm} \mathrm{~min}^{-1}$, the spectral bandwidth was $2 \mathrm{~nm}$, and the light path was $10 \mathrm{~mm}$. Reduced-minus-oxidized difference spectra were recorded using samples that had been reduced with a few grains of solid sodium dithionite and oxidized with a few grains of ammonium persulphate. For the measurement of (reduced $+\mathrm{CO}$ )-minus-reduced spectra the contents of both the sample and reference cuvettes were reduced with sodium dithionite, and then $\mathrm{CO}$ gas was bubbled through the sample for $30 \mathrm{~s}$.

Sources of c-type cytochromes. Cytochromes $c_{\mathrm{H}}$ and $c_{\mathrm{L}}$, from Methylophilus methylotrophus, Methylobacterium extorquens AM1 and A. metholanicus were purified as previously described (Cross \& Anthony, 1980; O'Keeffe \& Anthony, 1980; Elliott \& Anthony, 1988). Cytochrome $c_{550}$ from $P$. denitrificans and cytochrome $c_{551}$ from $P$. aeruginosa were kind gifts of Dr Tony Long (this department) and Professor Colin Greenwood (University of East Anglia, UK), respectively. Equine cytochrome $c$ was obtained from Sigma.

Measurement of protein and haem. Proteins were assayed by the bicinchoninic acid protein assay (Smith et al., 1988) with bovine serum albumin standards in detergent buffers. Haem was determined as the pyridine haemochrome as described by Fuhrhop \& Smith (1975).

SDS-PAGE of proteins. Gels containing 10-15\% (w/v) acrylamide monomer, with a $3 \%$ stacking gel, were used in the discontinuous system of Laemmli (1970) for the estimation of molecular masses of proteins and the purity of protein preparations. Proteins were stained with Coomassie Brilliant Blue, as described by Weber \& Osborn (1975). Gels were stained for haem proteins with $3,3^{\prime}, 5,5^{\prime}$-tetramethylbenzi- dine (TMBZ) by the method of Thomas et al. (1976). Molecular masses were determined with Sigma Dalton Mark VII standard proteins.

Effects of phopholipids on oxidase activity and reconstitution into phospholipid vesicles. Phospholipids were prepared by drying known concentrations of phospholipid stocks under $\mathrm{N}_{2}$ gas and resuspending the residue into a known volume of $20 \mathrm{~mm}$-phosphate buffer $\mathrm{pH}(7.5)$ containing $0.1 \%$ Triton $\mathrm{X}-100$, followed by brief sonication in a bathtype sonicator as described by Wong \& Jurtshuk (1984). The effect of phospholipids was then determined by adding oxidase into mixtures of phospholipid and equine cytochrome $c(20 \mathrm{nmol})$ in the spectrophotometric assay. Delipidation of the oxidase was attempted by gel filtration (Superose 12), the oxidase being eluted from the column with $25 \mathrm{~mm}$-MOPS buffer containing $0.3 \mathrm{mM}$-dodecyl maltoside and $10 \%$ glycerol. In attempts to reconstitute partially-purified oxidase into phospholipid vesicles, oxidase ( $250 \mu$ l containing $50 \mu \mathrm{g}$ protein) was mixed with sonicated phospholipid (in $100 \mu \mathrm{l} 25 \mathrm{~mm}$-MOPS buffer, $\mathrm{pH} 6.8$, containing CHAPS, n-dodecylmaltoside or cholate) so that the lipid:protein ratio was between $10: 1$ and $1000: 1$. After 15 s sonication, the mixture was incubated on ice for $1 \mathrm{~h}$ before being diluted. 'Reconstituted oxidase' was separated from solubilized proteins by either passage down Sephadex G-50 column $(1 \times 5 \mathrm{~cm})$ or centrifugation at $100000 \mathrm{~g}$ for $1 \mathrm{~h}$.

\section{Results}

\section{Characterization of the membranes of A. methanolicus}

The spectra in Figs 1 and 2 show that membranes of methanol-grown bacteria contained only $b$ - and $c$-type cytochromes (absorbance at $558 \mathrm{~nm}$ and $554 \mathrm{~nm}$ ) and a CO-binding $b$-type cytochrome (cytochrome $o$ ) (trough at $432 \mathrm{~nm}$ ). There was no evidence for a CO-binding $a$-type or $d$-type cytochrome (no absorbance above $570 \mathrm{~nm}$ ).

TMPD was oxidized rapidly with a low affinity whereas cytochrome $c$ was oxidized less rapidly, but its affinity for the oxidase was much greater (Table 1). The oxidase responsible was inhibited non-competitively by low concentrations of azide with both substrates. The kinetic constants for this inhibition, and the relative rates of oxidation of TMPD and cytochrome, are similar to those previously published for the cytochrome co of M. methylotrophus (Froud \& Anthony, 1984).

The spectral characteristics, oxidation of high-potential substrates and the high sensitivity to azide indicate that the oxidase responsible for cytochrome oxidation in the membranes of $\boldsymbol{A}$. methanolicus is an $o$-type oxidase of the cytochrome co type.

\section{Solubilization of the o-type oxidase from A. methanolicus}

Use of $2.25 \%(\mathrm{v} / \mathrm{v})$ Triton $\mathrm{X}-100$ in the solubilization yielded only $17.4 \%$ oxidase recovery compared with $70 \%$ solubilization obtained by Froud \& Anthony (1984) using M. methylotrophus. A similar recovery (about $20 \%$ ) was 


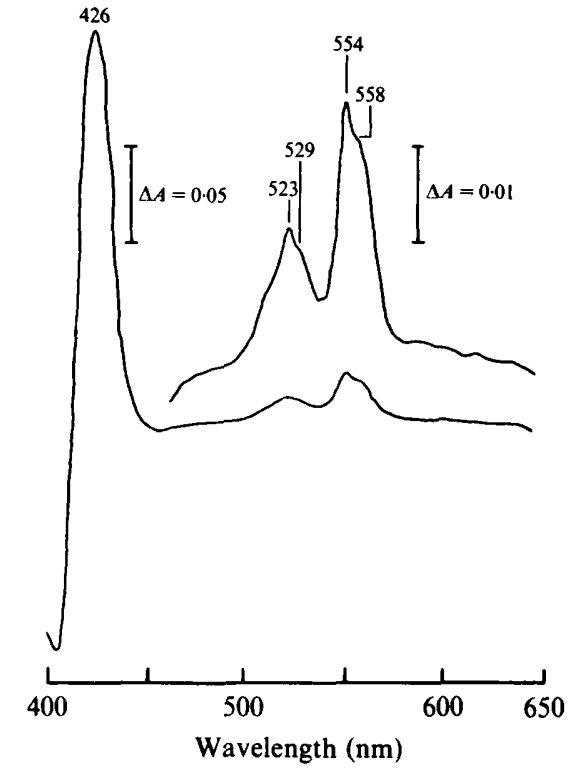

Fig. 1. Dithionite-reduced-minus-ammonium-persulphate-oxidized difference spectrum of the membranes of $A$. methanolicus. The difference spectrum of membranes $(2.75 \mathrm{mg}$ protein) suspended in $25 \mathrm{mM}$-MOPS buffer ( $\mathrm{pH} \mathrm{6.8)}$ was recorded at room temperature by adding a few grains of sodium dithionite into the sample cuvette and ammonium persulphate into the reference cuvette.

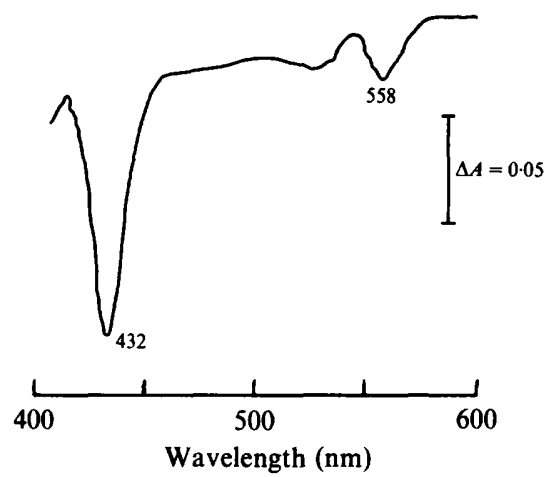

Fig. 2. (Reduced $+\mathrm{CO}$ )-minus-reduced difference spectrum of the membranes of $A$. methanolicus. Membrane suspension (as in Fig. 1 but with $3.25 \mathrm{mg}$ protein) in both cuvettes was reduced with sodium dithionite and $\mathrm{CO}$ gas bubbled through the sample cuvette for $30 \mathrm{~s}$ at room temperature. The spectrum was recorded after a further $5 \mathrm{~min}$. observed when n-octylglucoside ( $2.5 \%)$, n-dodecyl maltoside $(2 \%)$ or cholate $(25 \mathrm{~mm})$ was used to replace Triton $\mathrm{X}-100$.

Deoxycholate (in $25 \mathrm{mM}$-MOPS buffer, $\mathrm{pH} 7 \cdot 8$ ), on the other hand, solubilized about $85 \%$ of the oxidase with a sevenfold increase in specific activity. This was partly due to the twofold stimulation of activity by the residual detergent in the assay system. However, the deoxycholate-solubilized oxidase was found to be difficult to manipulate. For example, when it was precipitated by $15 \%$ ammonium sulphate the precipitate could not be resolubilized and gel filtration (in $25 \mathrm{mM}-\mathrm{MOPS} / 8 \mathrm{~mm}$ CHAPS, pH 7.8) resulted in $70 \%$ loss of activity after one passage down a Sephadex G-25 column equilibrated in the above buffer.

Zwittergent $_{3-12}(30 \mathrm{~mm})$, a zwitterionic detergent, which was used successfully in the purification of the $o$ and $d$-type oxidases of $E$. coli (Kita et al., 1984) and Klebsiella pneumoniae (Smith et al., 1990), solubilized almost all the cytochrome from the membranes, giving an orange-red soluble fraction and a creamy-white pellet. However, the soluble fraction showed very little activity and addition of $0.1 \%$ Tween 20 in the assay system did not result in higher activity.

CHAPS $(30 \mathrm{~mm})$, another zwitterionic detergent, solubilized $20 \%$ of the oxidase. Addition of $100 \mathrm{~mm}$ $\mathrm{MgCl}_{2}$ or $\mathrm{KCl}$, and brief sonication (15 s) during solubilization, did not improve the yield, but addition of

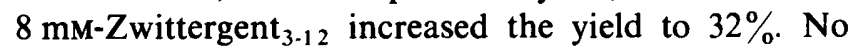
further improvement was obtained when a second round of solubilization of residual membrane was attempted using CHAPS $(20 \mathrm{~mm})$, cholate $(0 \cdot 2 \%)$ or Triton X-100 $(0.25 \%)$. Changing the protein:detergent ratio with CHAPS/Zwittergent resulted in little change in the yield of solubilized oxidase, when using between 5 and $10 \mathrm{mg}$ protein $\mathrm{ml}^{-1}$.

The procedure eventually adopted involved solubilization in MOPS buffer ( $25 \mathrm{mM}, \mathrm{pH} 6 \cdot 8)$ containing glycerol $(10 \%)$, CHAPS (25 mM) and Zwittergent $(8 \mathrm{~mm}$ ) (see Methods for details). About $32 \%$ of active oxidase could

Table 1. Kinetic parameters for the oxidase at different stages during purification

Activities were determined as described in Methods at pH 6.8 in 25 mM-MOPS buffer. The types of inhibition by sodium azide are given in parentheses: $\mathrm{C}$, competitive; $\mathrm{NC}$, non-competitive.

\begin{tabular}{|c|c|c|c|c|c|c|}
\hline \multirow[t]{2}{*}{ Substrate ... } & \multicolumn{3}{|c|}{ Ascorbate/TMPD } & \multicolumn{3}{|c|}{ Equine cytochrome $c$} \\
\hline & $\stackrel{V}{V}\left(\mu \mathrm{mol} \mathrm{min} \mathrm{min}^{-1} \mathrm{mg}^{-1}\right)$ & $\underset{(\mathrm{mM})}{K_{\mathrm{m}}}$ & $\underset{(\mu \mathrm{M})}{K_{\mathrm{i}}}$ & $\underset{\left(\text { nmol } \min ^{-1} \mathrm{mg}^{-1} \text { ) }\right.}{V}$ & $\underset{(\mu \mathrm{M})}{K_{\mathrm{m}}}$ & $\underset{(\mu \mathrm{M})}{K_{\mathrm{i}}}$ \\
\hline Membrane & $5 \cdot 6$ & 0.63 & $35(\mathrm{NC})$ & 31 & $13 \cdot 0$ & $8.8(\mathrm{NC})$ \\
\hline $\begin{array}{l}\text { Solubilized } \\
\text { oxidase }\end{array}$ & $3 \cdot 7$ & $2 \cdot 20$ & $100(\mathrm{NC})$ & 53 & $8 \cdot 3$ & $24 \cdot 0(\mathrm{NC})$ \\
\hline $\begin{array}{l}\text { Partially-purified } \\
\text { oxidase }\end{array}$ & $12 \cdot 8$ & $12 \cdot 50$ & $10^{4}(\mathrm{C})$ & 690 & $3 \cdot 1$ & $11.0(\mathrm{C})$ \\
\hline
\end{tabular}




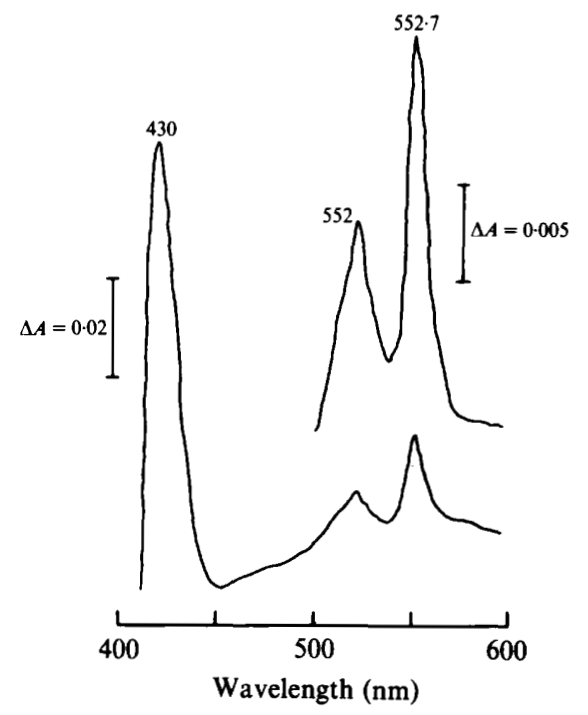

Fig. 3. Dithionite-reduced-minus-ammonium-persulphate-oxidized difference spectrum of the solubilized oxidase of $A$. methanolicus. The difference spectrum of solubilized oxidase $(0.5 \mathrm{mg}$ protein in $25 \mathrm{~mm}$ MOPS buffer, pH 6.8 , containing $25 \mathrm{mM}-\mathrm{CHAPS}$ and $8 \mathrm{mM}$-Zwittergent $_{3-12}$ ) was recorded at room temperature by adding a few grains of sodium dithionite into the sample cuvette and ammonium persulphate into the reference cuvette.

be routinely solubilized in this way, the oxidase having a $1 \cdot 7$-fold higher specific activity than that measured in the membrane preparation in the spectrophotometric assay. The solubilized oxidase could be stored indefinitely in liquid nitrogen.

\section{Characterization of the solubilized oxidase}

Identification of the cytochromes. Fig. 3 shows the presence of $c$-type cytochrome ( $\alpha$-peak at $552.7 \mathrm{~nm}$ ). No $560 \mathrm{~nm}$ shoulder due to cytochrome $b$ was detected, possibly due to large amounts of various membrane cytochromes $c$, but the CO-binding difference spectrum (Fig. 4) showed a $432 \mathrm{~nm}$ trough, similar to that seen in membrane preparations (Fig. 2), which is characteristic of a CO-reactive $b$-type cytochrome (cytochrome $o$ ).

Respiratory activity of the solubilized oxidase. The results in Tables 1 and 2 show that the solubilized oxidase had retained its activity with respect to oxidation of both TMPD and cytochrome $c$, and that inhibition by azide remained non-competitive in nature. The yield with respect to TMPD oxidation was only $13 \%$ compared with the $32 \%$ yield for cytochrome $c$ oxidation.

Stability of the solubilized oxidase. In the absence of salt the oxidase was stable at $4{ }^{\circ} \mathrm{C}$ between pH 4 and 6.8 , but $40 \%$ activity was lost over a $24 \mathrm{~h}$ period at $\mathrm{pH} 7 \cdot 8$. Over a period of $4 \mathrm{~h}$ at pH 6.8 ( $25 \mathrm{mM}$-MOPS buffer) in $200 \mathrm{~mm}$ -

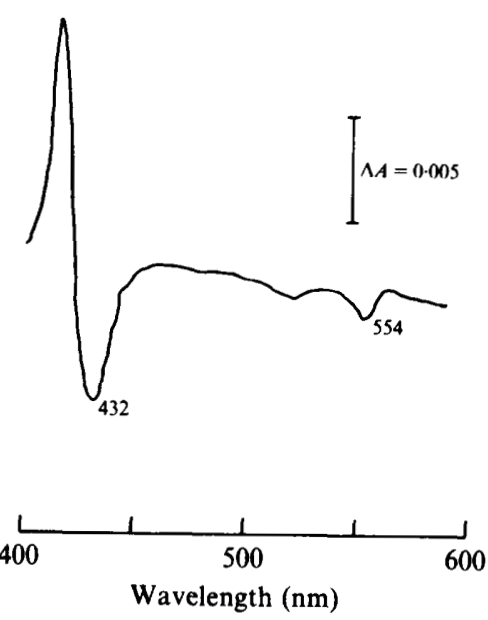

Fig. 4. (Reduced $+\mathrm{CO}$ )-minus-reduced difference spectrum of the solubilized oxidase of $A$. methanolicus. Solubilized oxidase (as in Fig. 3), in both cuvettes, was reduced with sodium dithionite and $\mathrm{CO}$ gas bubbled through the sample cuvette for $30 \mathrm{~s}$ at room temperature. The spectrum was recorded after a further $5 \mathrm{~min}$.

$\mathrm{NaCl}$ there was a $50 \%$ increase in activity (measured with cytochrome $c$ ) which then remained constant for at least $3 \mathrm{~d}$ at $4{ }^{\circ} \mathrm{C}$. This demonstrated that the oxidase from $A$. methanolicus is an exceptionally stable oxidase compared with the cytochromes $c o$ from other sources, which are very sensitive to changes of $\mathrm{pH}$ and salt concentration (e.g. see Carver \& Jones, 1983; Froud \& Anthony, 1984).

\section{Single-step partial purification of the o-type oxidase}

Table 2 summarizes the results of the partial purification of the oxidase by anion-exchange chromatography on DEAE-Sepharose. No further purification of the material eluting from DEAE-Sepharose was achieved by ionexchange chromatography, hydrophobic interaction chromatography, hydroxyapatite chromatography or gel filtration (see Methods).

\section{Cytochrome composition of the partially-purified oxidase.}

The dithionite-reduced-minus-ammonium-persulphateoxidized difference spectrum of the partially-purified oxidase (Fig. 5) was both interesting and surprising as it demonstrated the presence of $b$-type cytochromes but no $c$-type cytochrome. This was confirmed by the lowtemperature spectrum, which provided evidence for only one $b$-type cytochrome (Fig. 6). Some of the $b$-type cytochrome was $\mathrm{CO}$-reactive, implying the presence of cytochrome $o$ (Fig. 7). 
Table 2. Purification of cytochrome oxidase from membranes of A. methanolicus

Solubilization and purification procedures, and activities, were determined as described in Methods. The volumes for each purification step were $6.5 \mathrm{ml}, 13.9 \mathrm{ml}$ and $7.7 \mathrm{ml}$; and total activities ( $\mathrm{nmol}$ cytochrome oxidized min $^{-1}$ ) were 5507, 1752 and 690 for membranes, solubilized membranes and partially-purified oxidase respectively. A single purification step of anion-exchange chromatography on DEAE-Sepharose was used. This purification procedure was repeated many times, the results usually giving values within $10 \%$ of those presented below. Specific activities were measured in $25 \mathrm{mM}$-MOPS at pH 6.8 or in $50 \mathrm{~mm}-\mathrm{Tris} / \mathrm{HCl}$ (pH 7.0) for ubiquinol-1; they are expressed as nmol $\mathrm{min}^{-1}$ (mg protein) ${ }^{-1}$ for oxidation of equine cytochrome $c$ and nmol $\mathrm{O}_{2}{\text { consumed } \min ^{-1}(\mathrm{mg} \text { protein) }}^{-1}$ for oxidation of ascorbate/TMPD or ubiquinol-1.

\begin{tabular}{|c|c|c|c|c|c|c|c|c|c|}
\hline \multirow[t]{2}{*}{ Substrate... } & \multicolumn{3}{|c|}{ Cytochrome $c$} & \multicolumn{3}{|c|}{ Ascorbate/TMPD } & \multicolumn{3}{|c|}{ Ubiquinol-1 } \\
\hline & $\begin{array}{l}\text { Specific } \\
\text { activity }\end{array}$ & $\begin{array}{l}\text { Yield } \\
(\%)\end{array}$ & $\begin{array}{l}\text { Purification } \\
\quad \text { (-fold) }\end{array}$ & $\begin{array}{l}\text { Specific } \\
\text { activity }\end{array}$ & $\begin{array}{l}\text { Yield } \\
(\%)\end{array}$ & $\begin{array}{l}\text { Purification } \\
\text { (-fold) }\end{array}$ & $\begin{array}{l}\text { Specific } \\
\text { activity }\end{array}$ & $\begin{array}{c}\text { Yield } \\
(\%)\end{array}$ & $\begin{array}{l}\text { Purification } \\
\quad \text { (-fold) }\end{array}$ \\
\hline Membrane & 31 & 100 & $1 \cdot 0$ & 5595 & 100 & 1.0 & 971 & 100 & $1 \cdot 0$ \\
\hline $\begin{array}{l}\text { Solubilized } \\
\text { oxidase }\end{array}$ & 53 & 32 & $1 \cdot 7$ & 3743 & 13 & 0.7 & 183 & $2 \cdot 5$ & $0 \cdot 2$ \\
\hline $\begin{array}{l}\text { Partially-purified } \\
\text { oxidase }\end{array}$ & 690 & 18 & $22 \cdot 3$ & 12800 & 2 & $2 \cdot 3$ & 5252 & $3 \cdot 0$ & $5 \cdot 4$ \\
\hline
\end{tabular}

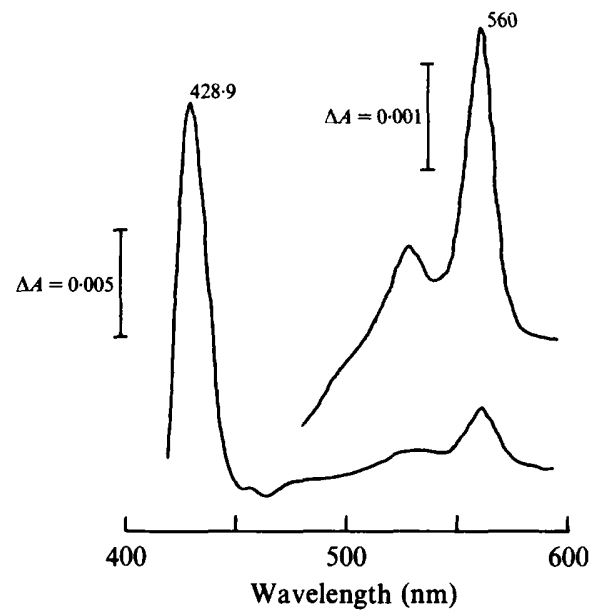

Fig. 5. Dithionite-reduced-minus-ammonium-persulphate-oxidized difference spectrum of the partially-purified oxidase of $A$. methanolicus. The spectrum of the oxidase $(50 \mu \mathrm{g}$ protein in $25 \mathrm{~mm}$-MOPS buffer, pH 6.8, containing $10 \%$ glycerol and 10 mM-CHAPS) was recorded at room temperature.

When a sample of the partially-purified oxidase was analysed by SDS-PAGE on a $15 \%$ acrylamide gel, no haem-staining band was present, confirming the absence of cytochrome $c$; protohaem IX dissociates from cytochrome $b$ under denaturing conditions and does not show up in the haem staining whereas the covalently-bound haem in cytochromes $c$ stains after gel electrophoresis (Goodhew et al., 1986). The absence of cytochrome $c$ was further confirmed by preparing the pyridine haemochrome derivatives of the oxidase; the only haem present was haem $b$. These results suggest that the solubilized oxidase, if it is a cytochrome $c o$, has lost the cytochrome $c$ component during the partial purification.

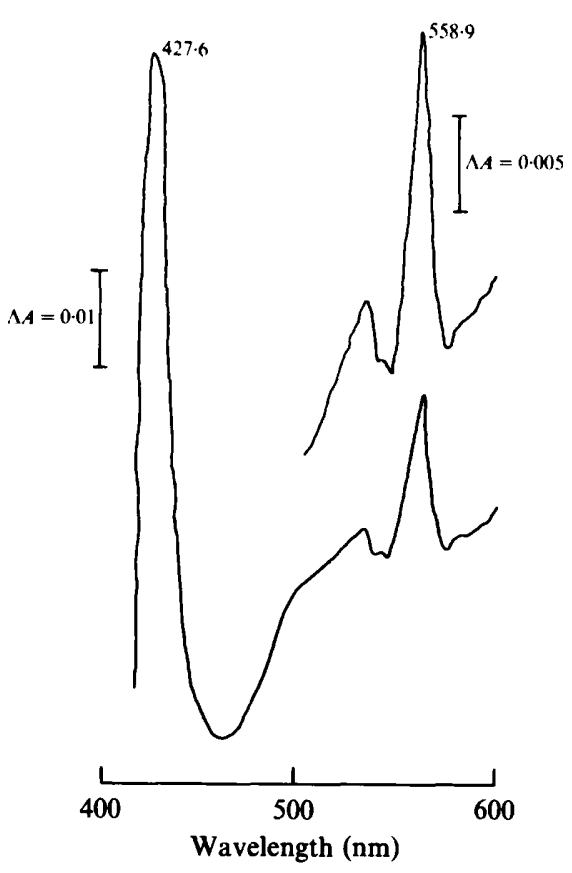

Fig. 6. Reduced-minus-oxidized difference spectrum at $77 \mathrm{~K}$ of the partially-purified oxidase from $A$. methanolicus. The spectrum of the oxidase (as in Fig. 5) was recorded at $77 \mathrm{~K}$ using $2 \mathrm{~mm}$ light path cuvettes, a spectral bandwidth of $0.5 \mathrm{~nm}$ and a scan speed of $50 \mathrm{~nm}$ $\min ^{-1}$.

\section{Respiratory activities catalysed by the partially-purified} oxidase

Oxidation of equine cytochrome $c$. In the spectrophotometric assay system at pH 6.8 (25 mM-MOPS buffer) the $V$ value for cytochrome $c$ oxidation was $690 \mathrm{nmol}$ 


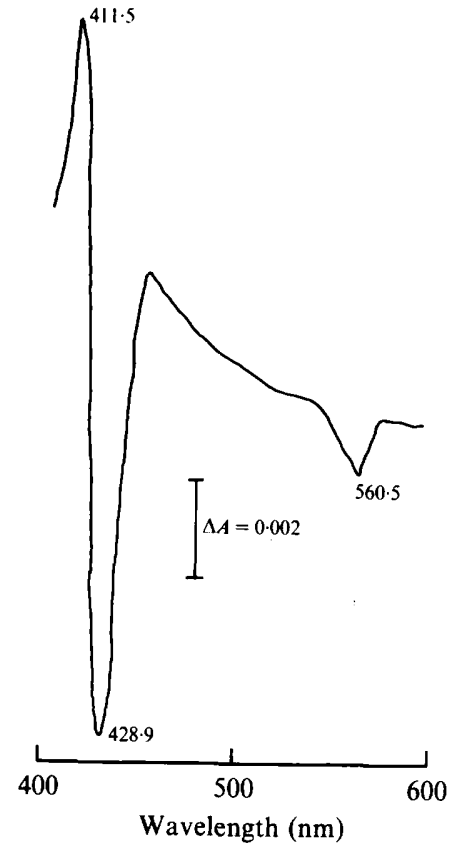

Fig. 7. (Reduced $+\mathrm{CO}$ )-minus-reduced difference spectrum of the partially-purified oxidase of $A$. methanolicus. Oxidase sample (as in Fig. 5 ) in both cuvettes was reduced with sodium dithionite and $\mathrm{CO}$ gas was bubbled through the sample cuvette for $30 \mathrm{~s}$ at room temperature. The spectrum was recorded after a further $5 \mathrm{~min}$.

$\min ^{-1} \mathrm{mg}^{-1}$ and the $K_{\mathrm{m}}$ value was $3 \cdot 1 \mu \mathrm{M}$ (Table 1). The $V$ value was about $20 \%$ of that measured with the cytochrome co of $M$. methylotrophus (Froud \& Anthony, 1984). The $K_{\mathrm{i}}$ values for azide and cyanide were $11.0 \mu \mathrm{M}$ and $4.8 \mu \mathrm{M}$ respectively, inhibition being competitive with respect to cytochrome $c$, a result different from that obtained with the solubilized oxidase.

Oxidation of ascorbate/TMPD. The specific activity for TMPD oxidation at pH 6.8 (25 mM-MOPS buffer) was much higher than that for equine cytochrome $c$ (Table 1), the $V$ value being $12.8 \mu \mathrm{mol} \mathrm{O}_{2} \mathrm{~min}^{-1} \mathrm{mg}^{-1}$, with a $K_{\mathrm{m}}$ value of $12.5 \mathrm{~mm}$. The $V$ value was about $30 \%$ of that measured with the pure cytochrome co from $M$. methylotrophus (Froud \& Anthony, 1984). As found for cytochrome $c$ oxidation, the inhibition by azide had changed during purification from being non-competitive to competitive in nature $\left(K_{\mathrm{i}}, 10 \mathrm{~mm}\right)$ (Table 1). This differs from the cytochromes co of $M$. methylotrophus and organism 4025 , where the $K_{\mathrm{i}}$ values were $1 \cdot 1 \mu \mathrm{M}$ and $0.2 \mu \mathrm{M}$ respectively and the inhibition was non-competitive with respect to TMPD (Carver \& Jones, 1983; Froud \& Anthony, 1984; Auton \& Anthony, 1989).

Although the specific activity for cytochrome $c$ oxidation increased 13 -fold during the single purification step, the specific activity with TMPD increased only 3.4fold (Table 2).
Oxidation of ubiquinol. The oxidation of ubiquinol was measured polarographically in the presence of $100 \mu \mathrm{M}$ ubiquinone-1 plus $8 \mathrm{~mm}$-dithiothreitol at $\mathrm{pH} 6.8(25 \mathrm{~mm}-$ MOPS buffer). On solubilization, about $97 \%$ of the activity was lost, presumably due to lack of solubilized cytochrome $b c_{1}$-complex; after partial purification, a 29fold increase in specific activity was observed (Table 2).

Effect of phospholipids on activity of the partially-purified oxidase

As seen in Table 3, the neutral lipids phosphatidylethanolamine and phosphatidylcholine had very little effect, whereas phospholipids with or negatively-charged head groups (phosphatidylglycerol and phosphatidylserine) stimulated the oxidase activity up to fourfold at a lipid:protein ratio of $10: 1$.

Attempts to prepare active delipidated oxidase and to reconstitute the partially-purified oxidase into membrane vesicles using the gel filtration and dilution methods described by Gennis (1989) were unsuccessful. Although in some cases haemoprotein was incorporated into vesicles no oxidase activity was ever recovered.

Identification of a putative cytochrome $c$ component of the oxidase

If the oxidase is a cytochrome co then its spectrum indicates that it must have lost the cytochrome $c$ component during the ion-exchange chromatography. In an attempt to identify the 'lost' cytochrome $c$ component, each eluted fraction from DEAE-Sepharose was added to the oxidase assay systems (with TMPD as substrate) to detect any stimulatory effect on oxidase activity. Only the cytochrome fraction which had not bound to DEAESepharose was active, giving an eightfold increase in the ascorbate/TMPD assay and a twofold increase when cytochrome $c$ oxidation was measured; it had no oxidase activity on its own. Boiling the stimulatory fraction for 10 min destroyed its activity, suggesting that the stimulation was not due to phospholipid.

SDS-PAGE of the stimulatory fraction revealed five haem protein bands $(19,21,26,48$ and $72 \mathrm{kDa})$. The $21 \mathrm{kDa}$ band was the only one that was absent from all those fractions that had failed to stimulate the activity of the partially-purified oxidase.

Ion-exchange chromatography with CM-cellulose or S-Sepharose at pH 5.5-6.5, or with DEAE-Sepharose at $\mathrm{pH} 8.0$ in the presence or absence of detergent, failed to resolve the proteins in the stimulatory fraction. Gel filtration on a Superose 12 column in $20 \mathrm{~mm}$ MOPS/100 mM- $\mathrm{NaCl}$ buffer (pH 6.8) containing $10 \mathrm{mM}$ - 
Table 3. Effects of phospholipids on the activity of the partially-purified oxidase

Activity was measured spectrophotometrically with equine cytochrome $c$ $(20 \mathrm{nmol})$ at $\mathrm{pH} 6.8$ in $25 \mathrm{~mm}$-MOPS buffer after pre-incubation of the oxidase with phospholipids for $15 \mathrm{~min}$ prior to assay. Duplicate experiments gave values within $10 \%$ of those given here, and when repeated with a different batch of partially-purified oxidase the values were within $20 \%$ of those given here, the trends and conclusions being identical. PE, phosphatidylethanolamine; PC, phosphatidylcholine; PG, phosphatidylglycerol; PS, phosphatidylserine.

\begin{tabular}{|c|c|c|c|c|}
\hline \multirow{3}{*}{$\begin{array}{l}\text { Phospholipid } \\
\text { (nmol) }\end{array}$} & \multicolumn{4}{|c|}{ Specific activity (nmol min-1 $\mathrm{mg}^{-1}$ ) } \\
\hline & \multicolumn{2}{|c|}{ Neutral phospholipids } & \multicolumn{2}{|c|}{ Charged phospholipids } \\
\hline & PE & PC & PG & PS \\
\hline None & 203 & 203 & 203 & 203 \\
\hline & 196 & 234 & 804 & 443 \\
\hline 200 & 205 & 225 & 820 & 740 \\
\hline 2000 & 193 & 237 & 0 & 0 \\
\hline
\end{tabular}

CHAPS resolved three peaks absorbing at $405 \mathrm{~nm}$. In order to determine which was the cytochrome $c$ component of the oxidase, a large-scale preparation was required, but a clear separation of the cytochromes was not achieved when gel filtration was performed with a Sephadex G-75 column in $50 \mathrm{~mm}-\mathrm{MOPS} / 100 \mathrm{~mm}-\mathrm{NaCl}$ ( $\mathrm{pH} 7.0$ ) containing $0.05 \%$ Triton X-100. However, only those fractions containing 19 and $21 \mathrm{kDa}$ cytochromes showed a stimulating effect on the oxidase. Although these fractions also contained some larger haem proteins, the $21 \mathrm{kDa}$ cytochrome was the only cytochrome that was absent from all fractions having no stimulatory effect. It was therefore concluded that the cytochrome $c$ component of the oxidase might be this $21 \mathrm{kDa}$ cytochrome.

The absorption spectrum of the fraction containing the $21 \mathrm{kDa}$ cytochrome confirmed the presence of $c$-type cytochromes. The CO-binding difference spectrum, recorded after bubbling $\mathrm{CO}$ for $30 \mathrm{~s}$, showed troughs at $551.4 \mathrm{~nm}$ and $427 \mathrm{~nm}$, suggesting the presence of a CObinding cytochrome $c$, similar to those present in the oxidase M. methylotrophus and organism 4025 (Froud \& Anthony, 1984; Auton \& Anthony, 1989).

\section{Cytochrome specificity of the partially-purified oxidase}

Because cytochrome $c_{\mathrm{L}}$ of $A$. methanolicus is rapidly autooxidized at about $\mathrm{pH} 7 \cdot 0$, the activity of the oxidase in the membrane was determined at $\mathrm{pH} \mathrm{5.6}$; the relative rates of oxidation of cytochrome $c_{\mathrm{H}}$, equine cytochrome $c$ and cytochrome $c_{\mathrm{L}}$ (all at $10 \mu \mathrm{M}$ ) were 45:23:1 respectively (Table 4). This confirms that cytochrome $c_{\mathrm{H}}$ is likely to be the physiological substrate for the oxidase of $A$. methanolicus, as found with other methylotrophs, and the complete failure to oxidize cytochrome $c_{\mathrm{L}}$ after solubilization and purification confirms this. The oxidase also failed to oxidize the cytochromes $c_{\mathrm{L}}$ from Methylophilus methylotrophus and Methylobacterium extorquens AM1.

The specific activity of the oxidase with cytochrome $c_{\mathrm{H}}$ $(10 \mu \mathrm{M})$ was $200 \mathrm{nmol} \mathrm{min}^{-1}(\mathrm{mg} \text { membrane protein })^{-1}$ and about $42 \%$ of this activity was obtained by solubilization. After purification on DEAE-Sepharose, the oxidase had lost most of its activity with cytochrome $c_{\mathrm{H}}$ but had retained $43 \%$ of its activity with equine cytochrome $c$ (Table 4). The explanation for this is related to the dramatic change in $\mathrm{pH}$ optimum for equine cytochrome $c$ after chromatography (see below). When measured at their $\mathrm{pH}$ optima, large losses of activity were observed for both $c$-type cytochromes, although more activity was lost with cytochrome $c_{\mathrm{H}}$ than with equine cytochrome $c$ (Table 4).

The $K_{\mathrm{m}}$ values for equine cytochrome $c$ and cytochrome $c_{\mathrm{H}}\left(K_{\mathrm{m}} 2-2.5 \mu \mathrm{M}\right)$ were rather lower than those measured for the cytochrome co from Methylophilus methylotrophus (14-32 $\mu \mathrm{M})$. The $V$ value at pH 5.6 (the $\mathrm{pH}$ optimum) was very low for cytochrome $c_{\mathrm{H}}(13 \mathrm{nmol}$ $\min ^{-1} \mathrm{mg}^{-1}$ ), but very much higher for equine cytochrome $c\left(700 \mathrm{nmol} \mathrm{min}^{-1} \mathrm{mg}^{-1}\right.$ at $\mathrm{pH} \mathrm{7.5}$, its $\mathrm{pH}$ optimum). The relatively low value for cytochrome $c_{\mathrm{H}}$ is due to the remarkable loss of activity during ionexchange chromatography. Addition of a small amount of reduced equine cytochrome $c(0.4 \mu \mathrm{M})$ to a reaction mixture containing $3.5 \mu \mathrm{M}$-cytochrome $c_{\mathrm{H}}$ and $3.6 \mu \mathrm{g}$ oxidase increased the rate of oxidation of cytochrome $c_{\mathrm{H}}$ 5.4-fold. This suggests that equine cytochrome $c$ acts as a replacement for the cytochrome $c$ of the co complex, 
Table 4. Oxidation of cytochrome $c_{\mathrm{H}}$ and equine cytochrome $c$

Activity was measured spectrophotometrically in 25 mM-buffer (MES at pH 5.6; MOPS at pH 6.8; CHES at $\mathrm{pH} 9 \cdot 5$ ). This purification procedure was repeated at least three times, the results usually giving values within $10 \%$ of those presented below. Assays contained $10 \mu \mathrm{M}$-cytochrome and the amount of protein indicated. The values in parentheses are to give an indication of yield at each stage of the purification.

\begin{tabular}{|c|c|c|c|c|c|}
\hline \multirow{3}{*}{$\begin{array}{c}\text { Substrate } \ldots \\
\qquad \mathrm{pH} \ldots\end{array}$} & \multicolumn{5}{|c|}{ Total activity $\left(\mu \mathrm{mol} \min ^{-1}\right)$} \\
\hline & \multirow{2}{*}{$\frac{\text { Cytochrome } c_{\mathrm{H}}}{5.6}$} & \multicolumn{3}{|c|}{ Equine cytochrome $c$} & \multirow{2}{*}{$\frac{\text { Cytochrome } c_{\mathrm{L}}}{5 \cdot 6}$} \\
\hline & & $5 \cdot 6$ & $6 \cdot 8$ & $9 \cdot 5$ & \\
\hline \multirow{3}{*}{$\begin{array}{l}\text { Membrane } \\
\text { Solubilized } \\
\text { oxidase } \\
\text { Partially-purified } \\
\text { oxidase }\end{array}$} & $7.0(100 \%)$ & $3.46(100 \%)$ & $6.4(100 \%)$ & $32.0(100 \%)$ & $0 \cdot 15(100 \%)$ \\
\hline & $2.93(42 \%)$ & $0.80(23 \%)$ & $1 \cdot 34(21 \%)$ & $6.7(21 \%)$ & $0.014(9 \%)$ \\
\hline & $0.014(0.2 \%)$ & $0.35(10 \%)$ & $0.60(9 \%)$ & $0.11(1.7 \%)$ & $0.00(0 \%)$ \\
\hline
\end{tabular}

Table 5. Relationship between $p H$ optima for various c-type cytochromes and their pI values, molecular masses and midpoint redox potentials

The ' $\mathrm{pH}$ optima' listed here refer to the $\mathrm{pH}$ tested between $\mathrm{pH} 5 \cdot 2$ and $9 \cdot 5$; the true optimum may be outside the range tested. The $\mathrm{pI}$ values, molecular masses and midpoint redox potentials are taken from the following sources: Pseudomonas aeruginosa from Horio et al. (1960); Methylophilus methylotrophus from Cross \& Anthony (1980); Methylobacterium extorquens AM1 from O'Keeffe \& Anthony (1980); equine cytochrome $c$ from Pettigrew \& Moore (1987).

\begin{tabular}{|c|c|c|c|c|c|}
\hline \multirow[b]{2}{*}{ Cytochrome } & \multicolumn{2}{|c|}{ 'pH optimum' } & \multirow[b]{2}{*}{$\begin{array}{c}\mathrm{pI} \\
\text { value }\end{array}$} & \multirow{2}{*}{$\begin{array}{c}\text { Mol. } \\
\text { mass } \\
(\mathbf{k D a})\end{array}$} & \multirow[b]{2}{*}{$\begin{array}{r}E_{\mathrm{m} 7} \\
(\mathrm{mV})\end{array}$} \\
\hline & $\begin{array}{l}\text { Solubilized } \\
\text { oxidase }\end{array}$ & $\begin{array}{l}\text { Partially-purified } \\
\text { oxidase }\end{array}$ & & & \\
\hline $\begin{array}{l}\text { Cytochrome } c-551 \\
(P . \text { aeruginosa })\end{array}$ & $5 \cdot 2$ & $>8.4$ & $4 \cdot 7$ & $8 \cdot 1$ & 286 \\
\hline $\begin{array}{l}\text { Cytochrome } c_{\mathrm{H}} \\
(\text { A. methanolicus })\end{array}$ & $5 \cdot 6$ & $5 \cdot 6$ & $5 \cdot 8$ & $9 \cdot 0$ & 224 \\
\hline $\begin{array}{l}\text { Cytochrome } c_{\mathrm{H}} \\
(M . \text { methylotrophus })\end{array}$ & $5 \cdot 2$ & $>8.4$ & 8.9 & $8 \cdot 5$ & 373 \\
\hline $\begin{array}{l}\text { Cytochrome } c_{\mathrm{H}} \\
(M . \text { extorquens AM1) }\end{array}$ & $7 \cdot 0$ & 7.0 & $8 \cdot 8$ & $11 \cdot 0$ & 294 \\
\hline $\begin{array}{l}\text { Cytochrome } c_{\mathrm{H}} \\
\text { (Horse heart) }\end{array}$ & 9.5 & 7.5 & $10 \cdot 5$ & 12.5 & 250 \\
\hline
\end{tabular}

enabling it to oxidize cytochrome $c_{\mathrm{H}}$ at a greater rate. When $0.5 \mathrm{mg}$ of the $21 \mathrm{kDa}$ cytochrome $c$ fraction was used to replace the small amount of equine cytochrome $c$ in the above 'reconstitution', the activity was increased about twofold, the lower increase compared with equine cytochrome $c$ being due, presumably, to the small amount of the $21 \mathrm{kDa}$ cytochrome $c$ present in the fraction used.

\section{pH optima for the oxidation of cytochromes $c$}

The $\mathrm{pH}$ optimum for the physiological substrate (cytochrome $c_{\mathrm{H}}$ ) was $\mathrm{pH} 5.6$ and was unchanged during purification (Fig. $8 a$; Table 4). This exceptionally low
$\mathrm{pH}$ optimum for an oxidase is probably related to the low $\mathrm{pH}$ optimum for growth.

The remarkable change in $\mathrm{pH}$ optimum from $\mathrm{pH} 9.5$ to $\mathrm{pH} 7.5$ for equine cytochrome $c$ during purification of the oxidase (Fig. $8 b$ ) is consistent with the proposal that the nature of the oxidase markedly changed during purification on DEAE-Sepharose. If the cytochrome $c$ component is lost then the $\mathrm{pH}$ optimum should tend to revert to the original if reconstituted with the oxidase cytochrome $c$. That this did occur was indicated by the observation that the $\mathrm{pH}$ optimum increased from $\mathrm{pH} 7.5$ to 8.5 when a small amount ( $1 \mathrm{mg}$ protein) of the fraction containing the $21 \mathrm{kDa}$ cytochrome $c$, previously shown to stimulate oxidation of equine cytochrome $c$, was 

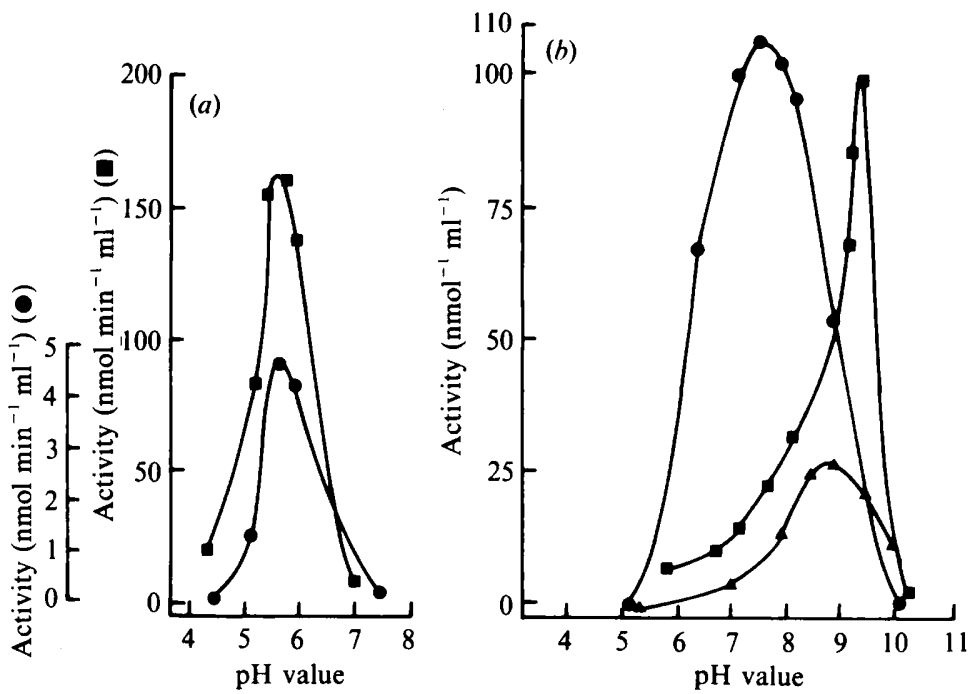

Fig. 8. $\mathrm{pH}$ optima for the oxidation of cytochromes $c$ during oxidase purification. The $\mathrm{pH}$ optima were determined with $(a)$ cytochrome $c_{\mathrm{H}}(10 \mu \mathrm{M})$ and $(b)$ equine cytochrome $c(20 \mu \mathrm{M})$ in $25 \mathrm{mM}$-buffer (formate, pH 4.0-4.2; acetate, pH 4.5-5.0; MES, pH 5.5-6.5; MOPS, $\mathrm{pH} 6.5-7.5$; Tris, $\mathrm{pH} 7 \cdot 0-9.0$; CHES, $\mathrm{pH} 9 \cdot 0-10 \cdot 0)$. The assay system contained either solubilized oxidase (21 $\mu \mathrm{g}$ protein) or partiallypurified oxidase $(7.4 \mu \mathrm{g}$ protein). $\boldsymbol{\square}$, Solubilized oxidase; $\boldsymbol{0}$, partially-purified oxidase; $\boldsymbol{\Delta}$, partially-purified oxidase plus $21 \mathrm{kDa}$ cytochrome $c$ fraction.

mixed with oxidase $(40 \mu \mathrm{g})$ for $30 \mathrm{~min}$ prior to incubation in the oxidase assay (Fig. $8 b$ ).

The pI values of cytochrome $c_{\mathrm{H}}$ and equine cytochrome $c$ are 5.8 and 10.5 and the $\mathrm{pH}$ optima were 5.6 and about 9.5 respectively. This suggested that the differences in the isoelectric points might reflect differences in the charged groups on the cytochromes $c$ which might influence their binding or electron transfer reactions. It was thus of interest to investigate the extent of this correlation with other cytochromes $c$. The results (Table 5) show that there is no clear relationship between the $\mathrm{pH}$ optimum for each cytochrome and their $\mathrm{pI}$ values, molecular masses or midpoint redox potentials. They also show that there was no apparent correlation between $\mathrm{pI}$ value and the change observed in the $\mathrm{pH}$ optimum during purification.

\section{Discussion}

The work presented in this paper confirms that the oxidase of the acidophilic methylotroph $A$. methanolicus is an $o$-type oxidase, although further confirmation by the use of photochemical action spectroscopy remains desirable (Poole, 1988). The solubilized membranes contained no $a$ - or $d$-type cytochromes and they oxidized the high-potential substrates cytochrome $c$ and TMPD at high rates. Oxidation of these substrates was very sensitive to azide, the inhibition being of the noncompetitive type. The rates of oxidation of cytochrome $c$ and TMPD by the partially-purified oxidase are similar to those measured with the cytochromes co of Rhodopseudomonas palustris (King \& Drews, 1976), Pseudomonas aeruginosa (Matsushita et al., 1982) and Methylophilus methylotrophus (Carver \& Jones, 1983; Froud \& Anthony, 1984). All these results suggest that $o$-type oxidase solubilized from the membranes is of the cytochrome $c o$ type. A further similarity to the cytochrome co of $M$. methylotrophus is the observation that the preferred cytochrome substrate from $A$. methanolicus is the cytochrome $c_{\mathrm{H}}$, activity with cytochrome $c_{\mathrm{L}}$, the electron acceptor from methanol dehydrogenase, being negligible. This is consistent with conclusions drawn from work with other methylotrophs in which the oxidase is cytochrome $c o$ or cytochrome $a a_{3}$ (Froud \& Anthony, 1984; Auton \& Anthony, 1989; Fukumori et al., 1985).

After partial purification, the active preparation changed markedly. The only CO-binding cytochrome remained cytochrome $o$ but there was no cytochrome $c$, and the only haem present was haem $b$. This suggests that the oxidase might be an atypical, azide-sensitive, cytochrome bo that is able to oxidize high-potential substrates. However, a more likely explanation is that it is a cytochrome $c o$ that has lost its cytochrome $c$, and in this respect it resembles some early descriptions of $o$-type oxidases which lost activity on purification, concomitant with loss of a cytochrome $c$ component (e.g. Yang \& Jurtshuk, 1978; Yang, 1985). The following dramatic changes in the properties of the oxidase after purification on DEAE-Sepharose argue strongly in support of this proposal. The most usual way of assaying oxidases of the cytochrome co type is to use the high-potential substrate 
TMPD, which is assumed to pass electrons directly to the cytochrome $c$ component of the oxidase. After purification of the solubilized oxidase, however, a high proportion of the TMPD oxidase activity was lost compared with activity with equine cytochrome $c$ (Table 2). The $K_{\mathrm{m}}$ value for TMPD oxidation had increased sixfold and its sensitivity to azide had decreased; the $K_{\mathrm{i}}$ value had increased 100-fold and the mode of inhibition had changed from non-competitive to competitive (Table 1).

Another major change occurring during purification was the loss of almost all activity towards the physiological substrate, cytochrome $c_{\mathrm{H}}$, compared with equine cytochrome $c$ (Table 4). Furthermore, although the $\mathrm{pH}$ optimum for cytochrome $c_{\mathrm{H}}$ oxidation remained unchanged, that for equine cytochrome decreased by $2 \mathrm{pH}$ units, and its sensitivity to azide inhibition changed from non-competitive to competitive.

The most obvious explanation for these changes is that the partially-purified oxidase consisted only of the cytochrome $o$ component and was only able to oxidize cytochrome $c$ when this could become 'reconstituted' into an active cytochrome $c o$. The equine cytochrome $c$ was apparently more able to effect this reconstitution, which could presumably only occur at a lower $\mathrm{pH}$ than its usual $\mathrm{pH}$ optimum. This is further supported by the observation that a small amount of equine cytochrome $c$ stimulated oxidation of the cytochrome $c_{\mathrm{H}}$ by the partially-purified oxidase. A fraction containing a $21 \mathrm{kDa}$ cytochrome $c$, obtained from the solubilized oxidase during the purification step, was also able to stimulate the oxidase and to raise the $\mathrm{pH}$ optimum for oxidation of equine cytochrome $c$.

Although all the results of this work are consistent with the conclusion that the oxidase is a cytochrome $c o$, it is worth noting that the distinctions between type of oxidase (cytochrome $a a_{3}$, bo or $c o$ ) and substrate specificity are not as well-defined as they once were; for example, there is considerable structural similarity between the cytochrome $a a_{3}$ from Paracoccus denitrificans, which oxidizes cytochrome $c$, and the cytochrome bo of E. coli, whose substrate is the low-potential substrate ubiquinol (Saraste et al., 1988; Raitio et al., 1990).

We would like to thank the Croucher Foundation for a research studentship for H.T.C.C., and the SERC for financial support.

\section{References}

ANTHONY, C. (1982). The Biochemistry of Methylotrophs. London: Academic Press.

ANTHONY, C. (1986). The bacterial oxidation of methane and methanol. Advances in Microbial Physiology 27, 113-210.

ANTHONY, C. (1988). Quinoproteins and energy transduction. In Bacterial Energy Transduction, pp. 293-316. Edited by C. Anthony. London: Academic Press.
Auton, K. A. \& Anthony, C. (1989). The 'methylamine oxidase' system of an obligate methylotroph. Biochemical Journal 260, 75-79.

CAR Ver, M. A. \& Jones, C. W. (1983). The terminal respiratory chain of the methylotrophic bacterium Methylophilus methylotrophus. FEBS Letters 155, 187-191.

Castor, L. N. \& Chance, B. (1959). Photochemical determination of the oxidases of bacteria. Journal of Biological Chemistry 234, 15871589

CHANCE, B. (1953). The carbon monoxide compounds of the cytochrome oxidases. II. Photodissociation spectra. Journal of Biological Chemistry 202, 397-406.

Cross, A. R . \& ANTHONY, C. (1980). The purification and properties of the soluble cytochromes $c$ of the obligate methylotroph Methylophilus methylotrophus. Biochemical Journal 192, 421-427.

ElliotT, E. J. \& ANTHONY, C. (1988). The interaction between methanol dehydrogenase and cytochrome $c$ in the acidophilic methylotroph Acetobacter methanolicus. Journal of General Microbiology 134, 369-377.

FROUD, S. J. \& ANTHONY, C. (1984). The purification and characterization of the o-type oxidase from Methylophilus methylotrophus, and its reconstitution into a 'methanol oxidase' electron transport chain. Journal of General Microbiology 130, 2201-2212.

FUHRHOP, J. H. \& SMITH, K. M. (1975). Laboratory methods. In Porphyrins and Metalloporphyrins, pp. 757-869. Edited by K. M. Smith. Amsterdam: Elsevier.

FukUmori, Y., Nakayama, K. \& Yamanaka, T. (1985). Cytochrome $c$ oxidase of Pseudomonas AMl: purification, and molecular and enzymatic properties. Journal of Biochemistry 98, 493-499.

GENNIS, R.B . (1989). Biomembranes: Molecular Structure and Function. New York: Springer.

Goodhew, C. F., Brown, K. R. \& Pettigrew, G. W. (1986). Haem staining in gels, a useful tool in the study of bacterial $c$-type cytochromes. Biochimica et Biophysica Acta 852, 288-294.

Horio, T., Higashi, T., Sasagawa, H., Kusai, K., Nakai, M. \& OKunuki, K. (1960). Preparation of crystalline Pseudomonas cytochrome $c-55 \mathrm{I}$ and its general properties. Biochemical Journal 77, 194-201.

Hunter, D. J. B., Brown, K. R. \& Pettigrew, G. W. (1989). The role of cytochrome $c_{4}$ in bacterial respiration. Cellular location and selective removal from membrane. Biochemical Journal 262, 233-240.

JuRTShuk, P., Mueller, T. M. \& WoNG, T. Y. (1981). Isolation and purification of the cytochrome oxidase of Azotobacter vinelandii. Biochimica et Biophysica Acta 637, 374-382.

KING, M. \& DREWS, G. (1976). Isolation and partial characterization of the cytochrome oxidase from Rhodopseudomonas palustris. European Journal of Biochemistry 68, 5-12.

KitA, K., Konishi, K. \& ANRAKU, Y. (1984). Terminal oxidases of Escherichia coli respiratory chain. Purification and properties of cytochrome $b 562-o$ complex from cells grown in the early exponential phase of aerobic growth. Journal of Biological Chemistry 259, 3368-3374.

LAEMMLI, U. K. (1970). Cleavage of structural proteins during the assembly of the head of bacteriophage T4. Nature, London 227, 680685.

Matsushita, K., Shinagawa, E., Adachi, O. \& Ameyama, M. (1982). $o$-type cytochrome oxidase in the membrane of aerobically-grown Pseudomonas aeruginosa. FEBS Letters 139, 255-258.

Matsushita, M., Shinagawa, E., Adachi, O. \& Ameyama, M. (1987). Purification, characterization and reconstitution of cytochrome oxidase from Gluconobacter suboxydans. Biochimica et Biophysica Acta 894, 304-312.

O'KeEFFE, D. T. \& ANTHONY, C. (1980). The two cytochromes $c$ in the facultative methylotroph Pseudomonas AMI. Biochemical Journal 192, 411-419.

Pettigrew, G. W. \& Moore, G. R. (1987). Cytochrome c: Biological Aspects. London: Springer.

Poole, R. K. (1983). Bacterial cytochrome oxidases: a structural and functionally diverse group of electron transfer proteins. Biochimica et Biophysica Acta 726, 205-243.

Poole, R. K. (1988). Bacterial cytochrome oxidases. In Bacterial Energy Transduction, pp. 231-291. Edited by C. Anthony. London: Academic Press. 
Raitio, M., Pispa, J. M., Metso, T. \& Saraste, M. (1990). Are there isoenzymes of cytochrome $c$ oxidase in Paracoccus denitrificans? FEBS Letters 261, 431-435.

Saraste, M., Rattio, M., Jalli, T., Chepuri, V., LemieuX, L. \& GeNNIS, R. B. (1988). Cytochrome $o$ from Escherichia coli is structurally related to cytochrome $a a_{3}$. Annals of the New York Academy of Sciences 550, 314-324.

SMITH, A., Hill, S. \& ANTHONY, C. (1988). A haemoprotein is not involved in the control by oxygen of enteric nitrogenase synthesis. Journal of General Microbiology 134, 1499-1507.

Smith, A., Hill, S. \& ANTHONY, C. (1990). The purification, characterization and role of the $d$-type cytochrome oxidase of Klebsiella pneumoniae during nitrogen fixation. Journal of General Microbiology 136, 171-180.

SONE, N., KUTOH, E. \& SATo, K. (1990). A cytochrome o-type oxidase of the thermophilic bacterium PS3 grown under air-limited conditions. Journal of Biochemistry 107, 597-602.

Steudel, K. \& Babel, W. (1982). Das Cytochromkomplement des methylotrophen Essigsaurebakteriums MB58 in Abhangigkeit von dem Wachstumsbedingungen. Zeitschrift für allgemeine Mikrobiologie 22, 379-388.

StEUdel, K., Miether, D. \& BabEL, W. (1980). Bakterium MB58, ein methylotrophes 'Essigsaurebakterium'. Zeitschrift für allgemeine Mikrobiologie 20, 633-672.
Thomas, P. E., Ryan, D. \& Levin, W. (1976). An improved staining procedure for the detection of the peroxidase activity of cytochrome P450 on SDS-polyacrylamide gels. Analytical Biochemistry 75, 168 176.

Uhlig, H., Karbaum, K. \& Steudel, A. (1986). Acetobacter methanolicus sp. nov., an acidophilic facultatively methylotrophic bacterium. International Journal of Systematic Bacteriology 36, 317322.

Weber, K. \& Osborn, M. (1975). Proteins and sodium dodecyl sulphate: molecular weight determination on polyacrylamide gels and related procedures. In The Proteins, 3rd edn, vol. 1, pp. 179-223. Edited by H. Neurath \& R. L. Hill. London: Academic Press.

Wong, T. Y. \& JURTshuk, P. (1984). Activation studies by phospholipids on the purified cytochrome $c_{4}: 0$ oxidase of Azotobacter vinelandii. Journal of Bioenergetics and Biomembranes 16, 477-489.

YANG, T. Y. (1986). Biochemical and biophysical properties of cytochrome $o$ of Azotobacter vinelandii. Biochimica et Biophysica Acta 848, 342-351.

YANG, T. Y. \& JURTSHUK, P. (1978). Purification and characterization of cytochrome $o$ from Azotobacter vinelandii. Biochimica et Biophysica Acta 502, 543-548. 